\title{
The Indian Science Congress.
}

THERE is a real danger that the severe retrenchment in public expenditure now in progress in India may lead to a curtailment of activities in those departments in which such restriction is least desirable, namely, the educational and scientific services devoted respectively to the training of workers and the investigation and development of the resources of the country. It was therefore very opportune that the presidential address delivered at the Indian Science Congress which has completed its tenth session at Lucknow (January 8-I3) emphasised the danger of apathy towards scientific knowledge and the immense problems bearing upon the welfare of India still awaiting solution. The president, Sir M. Visvesvaraya, himself a distinguished engineer and for many years the successful administrator of one of the largest and most progressive of the Indian States, rightly laid stress on the appalling state of destitution in which quite Ioo million out of the total population of 320 million in the country live, and the necessity for scientific research to increase the food supply, raise the standard of living, develop resources and train the people for citizenship. The address contained constructive suggestions towards stimulating research, promoting co-operation and concentration of effort and making the results of scientific work both in India and abroad more readily available.

The sectional presidents dealt with a variety of subjects and their addresses were mostly of a general character. A few words regarding each must suffice, and those who are interested will no doubt refer to the complete report which will before long be published by the Asiatic Society of Bengal. In his discourse to the Section of Physics and Mathematics, Dr. S. K. Banerji reviewed recent theories regarding the origin of cyclones and discussed in particular the cyclones of the Indian seas, their origin, movements and disappearance. He favoured the view that counter currents having their origin in differences in temperatures over large geographic areas initiate the conditions that give rise to a system of gyrating winds in these storms, and that the condensation of water vapour supplies the energy necessary to maintain them for a long period of time. Dr. MeIdrum in a brief opening address to the Section of Chemistry made out a case for regarding the study of this subject as a liberalising influence.

Mrs. Howard in her address to the Botanical Section dealt with the rôle of plant physiology in agriculture and indicated a number of directions in which botanical research is desirable, such as the factors underlying high quality in agricultural produce, the scientific interpretation of field experiments, the precise nature of various agricultural practices which come under the head of mutilations, the relations between physiology and the incidence of disease, and the basis of acclimatisation and change of seed. It was suggested that investigators in the Indian universities would find in these subjects many problems of great scientific interest and practical importance.

Dr. Pillai in his address to the Section of Agriculture epitomised recent researches in soil science. Prof. $G$. Matthai gave the Section of Zoology a very interesting survey of recent oceanographical research, with special reference to the Indian Ocean, dealing very fully with the physical and chemical factors influencing marine life and its distribution. Especially noteworthy was the reference to recent work on the colour of the light that penetrates by transmission and scattering into the depths of clear ocean water and its possible influence on the coloration of marine fauna and the development of their powers of vision. In the Section of Geology, Dr. Pascoe dealt with the palæography of Burma. Major Acton discoursed on the aims and economic value of medical research to the section devoted to this subject. The importance and interest attaching to the study of cultural anthropology was well emphasised by Dr. J. J. Modi in the section over which he presided.

A general survey of the work of the Congress indicates that scientific investigations in India are to a considerable extent directed by the special needs of the country, and indeed perhaps even more attention should be given than at present to subjects such as the chemistry of Indian natural products and problems arising therefrom. As an example of the kind of work being accomplished at present in this direction may be mentioned an interesting paper by J. L. Simonsen and M. Gopala Rao in which they showed that an exceedingly small proportion of pyrogallol added to Indian turpentine inhibits its tendency to oxidation for some months and thus adds greatly to its value. The practical side of research was also emphasised in a symposium of the Sections of Agriculture, Botany and Chemistry, in which a whole morning was devoted to the discussion of the nitrogen problem in Indian agriculture, and in another joint meeting, of the Sections of Botany and Agriculture, devoted to the improvement of fodder and forage in India. The same tendency is also found strongly reflected in the proceedings of some of the sections, notably in those just mentioned and in the Section of Medical Research.

Fundamental research as distinguished from applied science was strongly represented in the physics section of the Congress, and this was largely owing to the influence of the Calcutta school which has grown up during the past few years. Among some of the papers which dealt with new fields of research may be mentioned one by Mr. K. Seshagiri Rao on the scattering of light in fluids at low temperatures. A remarkable fact elicited by recent work (see Proc. Roy. Soc., November I922, p. I59) is that the light transversely scattered in liquids which at ordinary temperatures is very imperfectly polarised increases in intensity and at the same time becomes more and more completely polarised as the temperature is raised towards the critical point. In Mr. Seshagiri Rao's work, the study of the scattering is carried down to low temperatures, and an effect of the opposite kind is noticed. The quantitative results promise to throw light on the nature and magnitude of the thermal agitation of the molecules at low temperatures. An analogous investigation by Mr. Lalji Srivastava on the scattering of light in crystals was also presented to the Congress.

There is scarcely space to refer here in detail to the numerous other papers dealing with subjects so varied as vortex motion in fluids, formation of ripple-marks, earthquake coda, chromatic emulsions, acoustics of the pianoforte, whispering galleries, theory of band-spectra, temperature ionisation of gases, and a-ray tracks in argon and helium, to mention only a selection, presented to the section at Lucknow. A reference may, however, be made to a paper which evoked a most animated discussion at the meeting, that is one by the writer putting forward a new theory of the well-known blue colour of clear ice in glaciers (see NATURE, January 6). In reply to some of the points raised, attention was directed to the very remarkable fact that during the process of artificial crystallisation involved in the manufacture of ice, the suspended matter originally present in the water is rejected by the crystals as they form and accumulates in a pocket. Ice which shows the blue opalescence is quite free from colloidal matter of any kind.
C. V. Raman. 